\title{
POTENCIAIS SEQUÊNCIAS DE APRENDIZAGEM INTERCULTURAL NO TELETANDEM: A IMPORTÂNCIA DA MEDIAÇÃO
}

\author{
Queila Barbosa LOPES ${ }^{1}$ \\ Ana Carolina FRESCHI ${ }^{2}$
}

\begin{abstract}
Resumo: A partir da caracterização do Teletandem como Terceiro Espaço, onde o contato intercultural tem território privilegiado (KRAMSCH; URYU, 2014), e dos conceitos de competência intercultural (BELZ, 2003) e paráfrases (ORLANDI, 1987; 2000; PÊCHEUX, 1997), discutimos a relevância da identificação de potenciais sequências de aprendizagem intercultural (BORGHETTI et al., 2015) como oportunidades para melhor autocompreensão e autocrítica e desenvolvimento da competência intercultural a partir da mediação realizada no Teletandem. Assim, nosso artigo situa-se na interface entre Estudos Linguísticos, Estudos Culturais e Análise do Discurso de linha francesa. Os dados analisados foram coletados em 2011, 2012 e 2014 e tiveram como temas: preconceito linguístico e regional, eleições presidenciais, Copa do Mundo de futebol no Brasil e generalizações quanto à situação das escolas no Estado de São Paulo. Esses assuntos embasaram parte das interações e suscitaram diversas paráfrases que nos levaram aos questionamentos apresentados. Por meio da análise de quatro sessões de Teletandem de pares diferentes, pudemos identificar potenciais sequências de aprendizagem intercultural (PSAIs), o que demonstra o potencial do Teletandem como espaço desse tipo de aprendizagem. As sessões de mediação podem contribuir significativamente para o desenvolvimento dessa competência, auxiliando a compreender as identidades e o que entendemos ser a identidade que afirmamos ter. Esta contribuição poderá se efetivar pela ação problematizadora do mediador que, usando exemplos análogos ao que detectou na PSAI, poderia fazer questionamentos que ajudem o interagente a refletir sobre seu discurso, procurando colocar-se no lugar do outro.
\end{abstract}

Palavras-chave: Teletandem. Interculturalidade. Sequência de aprendizagem intercultural. Paráfrases. Mediação.

\footnotetext{
${ }^{1}$ UNESP - Universidade Estadual Paulista "Júlio de Mesquita Filho" - Programa de Estudos Linguísticos da Universidade Estadual Paulista "Júlio de Mesquita Filho". São José do Rio Preto - São Paulo - Brasil. 15054-000 - queilalopes@gmail.com

2 UNESP - Universidade Estadual Paulista “Júlio de Mesquita Filho" - Programa de Estudos Linguísticos. São José do Rio Preto - São Paulo - Brasil. 15054-000 - anafreschi@ gmail.com
}

http://dx.doi.org/10.21165/gel.v13i3.1470 


\section{Introdução}

As práticas identitárias são acontecimentos que nos constituem e, em certa medida, norteiam nossas escolhas cotidianas. Em nossas ações, deixamos marcas do que somos e em que acreditamos. O papel da cultura nesse cenário não pode ser negligenciado. Kramsch e Uryu (2014, p. 212) definem contato intercultural como "um estado de coisas em que pessoas de diferentes culturas entram em contato". Quando estamos nessa situação de contato com aquele que sabe muito pouco quem somos nós, destacam-se aos nossos olhos as marcações das diferenças (WOODWARD, 2000) entre as culturas e fica mais evidente a nós mesmos quem somos, pois nos constituímos na alteridade.

Com o auxílio das tecnologias digitais de comunicação e informação, esses contatos interculturais online se tornaram mais factíveis e a custo muito reduzido, principalmente, considerando que, antes do advento destas tecnologias, contávamos com as mensagens escritas (que demoravam para chegar aos seus destinos) ou teríamos que nos deslocar para os locais de outras culturas a preços que apenas poucos brasileiros podiam/podem arcar. O Teletandem, contexto virtual, autônomo e colaborativo de ensino-aprendizagem de línguas estrangeiras (TELLES, 2009) é um dos ambientes em que os encontros interculturais regulares ocorrem a baixo custo, comparando-se com o investimento necessário para realizar uma viagem ao exterior ou mesmo manter contato com um estrangeiro via ligações telefônicas.

No entanto, há questionamentos ${ }^{3}$ que consideramos necessários para que as experiências de encontros interculturais efetivamente contribuam para o desenvolvimento da competência intercultural (HELM, 2009; BELZ, 2003). De acordo com Belz (2003), a competência intercultural é definida como a tomada de consciência e/ou compreensão das atitudes estrangeiras, de suas crenças e também de suas práticas linguísticas. Defendemos a ideia de que tal desenvolvimento seja indispensável para uma convivência frutuosa neste mundo cada vez mais plural e cujas fronteiras são fluidas assim como as

\footnotetext{
${ }^{3}$ Como por exemplo: Que "identidades" são solidificadas em nossos discursos? Que imagem do meu país e do país do outro constituem nosso imaginário e surgem durante as interações? Concordamos com o que é dito sobre nós? Somos quem a mídia diz que somos? Que preconceitos estão impregnados em nossos discursos? Espero que o outro corresponda à imagem que tenho do "estrangeiro"?
} 
identidades pós-modernas (BAUMAN, 2001). Identidades construídas sobre a égide das redes sociais, da produção e compartilhamento de conteúdo.

$\mathrm{O}$ acesso facilitado à internet e suas possibilidades, em que as fronteiras/limites geográficos não são obstáculos para a comunicação e o contato com a alteridade (estrangeiro) é bem mais factível que há alguns anos, pode contribuir para suscitar questionamentos sobre si mesmos, o que implica na necessidade cada vez mais latente de desenvolvimento de competência intercultural para o bom convívio e o compartilhamento/desenvolvimento de conhecimento que auxiliará a todos.

Neste trabalho, analisamos os dados de quatro interações das quais destacamos seis excertos para a análise (a fim de organização, elas serão designadas como Interação A, Interação B, Interação C e Interação D) entre estadunidenses e brasileiras, num total de quatro pares - oito interagentes. Nesses pares, o que mais se destacou foi a presença do que consideramos paráfrases discursivas, definida por Orlandi (1987) como um "retorno constante a um mesmo dizer sedimentado" (p. 27), ou seja, processos vistos como a repetição, a reiteração de discursos veiculados numa sociedade sem a preocupação nem intenção de rompimento com eles. Embora essas paráfrases tenham sido mais presentes em um par do que em outros, percebemos que eles ocorrem com alguma frequência entre os interagentes, o que justifica a opção por identificar e analisar esses momentos das interações como potenciais sequências de aprendizagem intercultural.

Acreditamos que as condições de produção, assim como a mediação de Teletandem, podem ter um impacto positivo no desenvolvimento da competência intercultural do aprendiz de língua estrangeira, por meio da identificação das potenciais sequências e da aprendizagem intercultural. As perguntas que nos guiam nessa empreitada são: "Quais seriam as marcas discursivas que evidenciariam os momentos identificados como potenciais sequências de aprendizagem intercultural numa sessão de interação no Teletandem? E como essas potenciais sequências de aprendizagem intercultural podem contribuir para as sessões de mediação?”. 


\section{Fundamentação teórica}

\section{Teletandem e cultura}

O Teletandem (TELLES, 2006; TELLES, 2011) é um contexto de ensinoaprendizagem no qual pares de falantes de línguas diferentes trabalham de forma autônoma e colaborativa para aprender a língua um do outro por meio de encontros virtuais com uso da tecnologia VoIP - imagens de webcam, voz e texto (TELLES, 2015). Quando o Teletandem é institucionalizado, ou seja, reconhecido pela instituição de ensino onde ocorre (ARANHA; CAVALARI, 2014), como nesta pesquisa, além das sessões de interação, os participantes podem contar com sessões de orientação, ou tutoriais, antes do início das interações, bem como com sessões de mediação, que são:

[...] encontros entre o interagente (aluno universitário praticante de Teletandem) e o mediador (aluno de pós-graduação) para que possam discutir aspectos relacionados à prática do interagente e refletir juntos sobre as dúvidas e os problemas encontrados no ensino e aprendizagem de línguas nas sessões de Teletandem, questões culturais, assim como possíveis impasses entre parceiros. O mediador se coloca para o interagente como um parceiro de discussão, fazendo, assim, a intermediação da aprendizagem segundo pressupostos vigotskyanos, de desenvolvimento por meio da interação social e por meio do oferecimento de andaimes (SALOMÃO, 2012, p. 20).

Neste contexto, de acordo com Telles e Ferreira (2010), além da aprendizagem linguística, há a possibilidade de discussões acerca de questões sociais, econômicas, culturais e políticas. Mais especificamente, discutiremos neste artigo o contato intercultural e os tópicos diretamente relacionados a tal contato, tais como (a) a necessidade de desenvolvimento de competência intercultural e (b) a reflexão sobre os processos parafrásticos.

Bhabha (1998), Kramsch e Uryu (2014) afirmam que os espaços de contato intercultural são um Terceiro Espaço, as novas zonas de desenvolvimento proximais (as ZDPs vigostkianas).

Nas palavras de Bhabha (1998),

[...] deveríamos lembrar que é o "inter" - o fio cortante da tradução e da negociação, o entrelugar - que carrega o fardo do significado da cultura. Ele permite que se comecem a vislumbrar as histórias 
nacionais, antinacionalistas, do "povo". E ao explorar esse Terceiro Espaço, temos a possibilidade de evitar a política da polaridade e emergir como os outros de nós mesmos. (BHABHA, 1998, p. 69)

Assim, o Terceiro Espaço se constitui naquele lugar não geográfico em que procuro deixar de colocar todos os demais sob o meu parâmetro cultural, procurando desnudar-me de julgamentos, objetivando observar o outro a partir dele mesmo para aprender mais dele e de mim mesmo.

Dessa forma, o Terceiro Espaço, lugar da negociação/colaboração, pode nos auxiliar a nos compreender melhor, nos instrumentalizando com a capacidade de não mais nos vermos (nem a qualquer outro povo/nação) como "modelo", segundo o qual os demais modelos devam ser comparados ou hierarquizados. Assim, estaríamos desenvolvendo a competência intercultural, assumindo uma identidade aberta à alteridade. Considerando o Teletandem, entendemos que esse espaço de comunicação síncrona pode se constituir nesse Terceiro Espaço, a começar de seus princípios: a reciprocidade e a autonomia. O Teletandem é espaço de negociação de sentidos, de modos de correção, de ideias e reflexão compartilhada, se caracterizando assim como um local no qual os aprendizes de línguas estrangeiras, como parceiros interagentes, têm oportunidade para o desenvolvimento do que Belz (2003) designa competência intercultural.

Segundo Belz (2003), o desenvolvimento dessa competência demanda atitudes a serem desenvolvidas no aprendiz/parceiro (em nosso contexto de pesquisa do Teletandem costumamos designar como "parceiro" aquele com que realizamos a prática de Teletandem). Quando se desenvolve essa competência "[...] o interesse do falante intercultural no outro é distinto dos interesses de outras pessoas cuja interação com o outro é motivada pelo ganho econômico ou pela fascinação com o "exótico" (BELZ, 2003, p. 72). O parceiro de Teletandem estaria, assim, menos propenso a julgamento de valor no tocante à cultura do outro e manteria atitude de disposição e genuíno interesse pelo ponto de vista do outro a respeito dos fenômenos culturais observados em seus contextos. Citando Byram (1997 apud BELZ, 2003), Belz reitera que o falante intercultural não coleta simplesmente fatos sobre a cultura estrangeira, mas coloca as informações a que está exposto em diálogo com informações sobre sua própria cultura, tendo habilidade de tecer críticas sobre ela. 
Na mesma esteira de Belz, Helm (2009) endossa a existência de componentes ou conhecimentos (savoirs), os quais são quesitos para a competência intercultural. Dentre eles destacamos, para fins da reflexão que nos propomos neste artigo, a consciência cultural crítica. Segundo Helm (2009, p. 94), essa seria "a capacidade de avaliar, de forma crítica e com base em critérios explícitos, perspectivas, práticas e produtos em suas próprias e outras culturas e países".

No entanto, apontamos para a necessidade de se oportunizar reflexões que contribuam para o desenvolvimento dessa competência, a qual parece (ou tende a) não ocorrer naturalmente. O Teletandem, como Terceiro Espaço de encontros interculturais, se mostra propício para esse objetivo, como postulamos, a partir da identificação das potenciais sequências de aprendizagem intercultural. Segundo Borghetti (2015), essas sequências envolvem: (i) exemplificações e equivalências entre fenômenos; (ii) casos nos quais os estudantes tentam comunicar sua compreensão aos outros e (iii) circunstâncias de adaptação à contribuição do outro (p. 14). Podemos perceber nos dados analisados que há presença destes três itens e, a depender dos parceiros, maior ocorrência do primeiro e segundo, sendo que nem sempre se pode afirmar, apenas a partir da interação, se ocorreu o terceiro item.

A tese defendida neste artigo se apoia no pressuposto de que, a partir da identificação dos momentos elencados por Borghetti como constitutivos das PSAIs, nas interações em Teletandem, poderíamos, então, identificar as potenciais sequências de aprendizagem intercultural deste contexto virtual de aprendizagem e, então, utilizá-las para facilitar ou articular contextos para o desenvolvimento dessa competência intercultural. Procuraremos responder como essas potenciais sequências de aprendizagem intercultural podem contribuir para o Teletandem na seção em que discutiremos implicações pedagógicas.

\section{Teletandem e processos parafrásticos}

Neste estudo, em especial, destaca-se a paráfrase discursiva (ORLANDI, 1987; 2000; PÊCHEUX, 1997). Desse modo, sentimos a necessidade de realizar um trabalho com interface entre Estudos Linguísticos, Culturais e a Análise de Discurso (AD). Aqui nos referimos especificamente à $\mathrm{AD}$ de linha francesa e como se entende nessa área o que 
são os processos parafrásticos que estiveram presentes na interação. Dada a onipresença da paráfrase não apenas em uma das interações, mas também em mais três interações, concluímos ser relevante discutir aqui tal conceito, relacionando-o com o de competência intercultural.

Em excertos de interações encontrados em pesquisas realizadas no projeto Teletandem (MARTINS MOITEIRO, 2009; ZAKIR, 2015), também encontramos processos parafrásticos, assim como em nossas atuais mediações em grupos de Teletandem ${ }^{4}$. Essa realidade nos instigou a discutir esses processos nesta investigação por nos dispormos a trabalhar, aqui, questões ligadas à interculturalidade. Esta última, por sua vez, se relaciona à alteridade e à constituição da própria identidade, a partir do olhar para o outro, identificando-o como 'não eu'.

Conforme dito anteriormente, segundo Orlandi (1987), a paráfrase é um "retorno constante a um mesmo dizer sedimentado" (p. 27). Nessa perspectiva, o sujeito discursivo, atravessado pela ideologia, reproduz discursos, contribuindo para sua difusão e sedimentação. Se esses processos, que nos remetem às noções de citacionalidade de Derrida (1988) e performatividade de Butler (1999), são possíveis entre indivíduos que compartilham de um mesmo espaço sociocultural, quando o contexto é entre culturas diferentes, então, o sujeito se sente com ainda mais autoridade e liberdade de realizar as paráfrases por ser, no caso do momento específico da interação intercultural, a fonte mais próxima, validante, confiável e com autoridade para dizer de si mesmo. Desse modo, nas interações de Teletandem, contexto específico, focado neste artigo, aquilo que um interagente diz de si mesmo, de sua cultura e de seu povo não costuma ser questionado pelo parceiro ${ }^{5}$, o que, sob nosso olhar, pode constituir como uma potencial sequência de aprendizagem intercultural.

\section{Metodologia}

\section{Caracterização da pesquisa}

Para responder aos questionamentos propostos, esta investigação vale-se de uma metodologia qualitativa (BURNS, 1999; GÜNTHER, 2006). Nos termos de Burns

\footnotetext{
${ }^{4}$ Os autores deste trabalho são mediadores de Teletandem.

${ }^{5}$ Essa aceitação da descrição de fatos culturais pelo parceiro se mostra pelo respeito ao que o outro diz de si, sem questionar ou duvidar do que ele compartilha sobre sua cultura.
} 
(1999), essa escolha justifica-se por: a) incluir interpretações socialmente subjetivas; b) apoiar-se nas sessões de interação oral para as interpretações e asserções; c) explorar as sessões sem controle das variáveis; d) buscar interpretar o fenômeno por meio da descrição e da análise; e) reconhecer que as interpretações são relativas somente ao contexto em que se encontram; e f) estar focada no processo. Além disso, assim como defende Günther (2006), esta investigação tem seu foco definido previamente e evidencia a realidade social por meio da construção e atribuição conjunta de significados dos sujeitos com a análise do processo interativo e reflexivo.

Também é possível identificar traços de natureza interpretativista (MOITA LOPES, 1994; DENZIN; LINCOLN, 2007), uma vez que este trabalho se vincula à realidade, construída pelo indivíduo com ele mesmo, e entende que o observador não é neutro e objetivo, dado que que ele tem uma posição histórica e se situa localmente como observador humano da condição humana. Do mesmo modo, esta investigação contém traços de um estudo de caso, dado que há a descrição de uma unidade ou caso (ANDRÉ, 2005) e o estudo de uma instância de um determinado fenômeno em profundidade (GIVEN, 2008).

\section{O contexto e os participantes do estudo}

Os dados foram coletados por meio de uma parceria para realização da prática de Teletandem entre alunos de duas instituições de ensino superior: uma brasileira e outra estadunidense. A instituição brasileira é pública e reconhecida como uma das melhores universidades brasileiras e latino-americanas. A instituição estadunidense é privada e reconhecida como uma das melhores universidades na área de humanidades nos Estados Unidos.

\section{Instrumentos e procedimentos de coleta e análise dos dados}

As sessões de Teletandem utilizadas neste trabalho foram gravadas em períodos diferentes. As sessões de interação do par A ocorreram no período entre março e abril de 2011; as do par B, entre março e abril de 2012, e as dos pares C e D, entre setembro e dezembro de 2014. Em todas as sessões, os participantes são aprendizes de inglês língua 
estrangeira, no caso das brasileiras, e de português língua estrangeira, no caso dos estadunidenses, das universidades supracitadas. Idealmente, as sessões deveriam ter duração de cerca de uma hora cada, sendo meia hora dedicada ao inglês e meia para o português; no entanto, percebemos que isso nem sempre acontece, o que pode ser ocasionado por problemas técnicos.

As sessões ocorreram por meio do Skype e foram gravadas pelo programa Screen Recorder for Macintosh. As gravações foram, então, transferidas para o Transana, programa de análise qualitativa de vídeos, e transcritas pelo verbatim.

Para a análise apresentada neste artigo, um recorte foi feito. Como buscamos selecionar momentos que podem ser considerados potenciais sequências de aprendizagem intercultural, procuramos por excertos em que os participantes brasileiros fazem uso de paráfrases para falarem sobre sua língua, seu país ou sua cultura. Selecionamos apenas uma sessão de cada par, no momento em que eles se comunicam em português e em que os processos parafrásticos estão presentes. Isso resultou em quatro sessões de interação, denominadas Interação $A$, Interação $B$, Interação $C$ e Interação D. A tabela abaixo mostra informações sobre os dados coletados.

\begin{tabular}{|c|c|c|c|c|}
\hline $\begin{array}{c}\text { Nome do par } \\
\text { analisado }\end{array}$ & $\begin{array}{c}\text { Nome da sessão } \\
\text { analisada }\end{array}$ & $\begin{array}{c}\text { Número da } \\
\text { sessão analisada }\end{array}$ & $\begin{array}{c}\text { Duração da } \\
\text { sessão analisada }\end{array}$ & Tempo analisado \\
\hline par A & Interação A & oitava sessão & $53 \min 05 \mathrm{~s}$ & $28 \min 17 \mathrm{~s}$ \\
\hline par B & Interação B & oitava sessão & $52 \min 56 \mathrm{~s}$ & $32 \mathrm{~min} 29 \mathrm{~s}$ \\
\hline par C & Interação C & segunda sessão & $53 \min 46 \mathrm{~s}$ & $28 \min 22 \mathrm{~s}$ \\
\hline par D & Interação D & terceira sessão & $1 \mathrm{~h} 8 \min 12 \mathrm{~s}$ & $34 \min 24 \mathrm{~s}$ \\
\hline
\end{tabular}

Tabela 1 - Organização dos dados coletados e analisados

\section{Características dos participantes}

Todos os nomes dos participantes serão substituídos por uma sigla que indica a sua origem e o par de qual fazem parte, por exemplo, no par A, tem-se o BraA, para o brasileiro participante desse par, e EstA, para o estadunidense participante desse par, e assim por diante. Tal medida foi tomada para fins de confidencialidade das informações pessoais dos participantes. 
No par A, BraA é aluna de Engenharia Biotecnológica da mesma universidade onde pratica Teletandem. Ela nunca viajou para fora do Brasil e, além do inglês, estuda alemão como língua estrangeira. EstA é aluno de pós-graduação da mesma universidade onde estuda português e pratica o Teletandem. Ele já viajou para fora de seu país e já estudou espanhol como língua estrangeira.

No par B, BraB é aluna de Letras (português/inglês) da universidade onde pratica o Teletandem. Ela nunca viajou para o exterior. EstB é aluno de graduação da universidade onde estuda português e pratica Teletandem. Ele já viajou para vários países e já estudou francês como língua estrangeira.

No par C, BraC é aluna de Letras (português/alemão) da mesma universidade onde estuda inglês e pratica Teletandem. Ela já fez intercâmbio para dois países e já estudou espanhol como língua estrangeira. EstC é aluna de graduação da mesma universidade onde estuda português. Ela também é fluente em espanhol e viveu alguns meses no Brasil, por meio de programa de intercâmbio.

Por fim, no par D, BraD é aluna de Letras (português/inglês) da universidade onde pratica Teletandem. Ela já viajou para os Estados Unidos. EstD é aluna de graduação onde estuda português e pratica Teletandem. Ela já viveu no Brasil por dez meses e já estudou espanhol como língua estrangeira.

\section{Análise de dados: identificação de processos parafrásticos}

Baseando-nos em Orlandi (1987; 2000) e Pêcheux (1997), por meio da seleção e análise dos trechos abaixo, procuramos obter dados para a discussão de potenciais sequências de aprendizagem intercultural para o desenvolvimento da competência intercultural.

Iniciamos com o par A. Durante a oitava sessão de interação, os interagentes estão conversando sobre viagens e meios de transporte quando a brasileira repete uma paráfrase que parece ser recorrente entre os interagentes. 
Excerto 1 (de 15'50” a 17’12”): Preconceito linguístico

BrA: não... na verdade, a gente usa muitas coisas... mas a gente nem percebe que... a gente tá usando... porque a gente fala desde que nasceu... mas a gente não usa tudo e não são todas as pessoas que usam corretamente... lógico que aqui na faculdade a gente melhora muito nosso português, porque a gente precisa escrever e ler muitas coisas... mas... é... bem.. poucas pessoas sabem falar o português corretamente... poucas pessoas... até eu mesmo erro muitas vezes... uso... palavras que deveriam... ou então conjugações que não ficam bonitas... não, não são sonoras [pausa longa] que a gente diz né que não são sonoras provavelmente... é bem complicado, as pessoas aqui no Brasil dificilmente falam o português correto [pausa longa] é mais fácil... é que na faculdade a gente aprende muito mais português inglês do que às vezes outras disciplinas [risos] por exemplo, no meu caso, porque a gente lê muito... e estuda muito para escrever as coisas direito [pausa longa] eu escrevi um artigo que vou publicar no meio do ano... e... o meu maior problema é o português correto e a tradução pro inglês porque... os resultados e as coisas eu sei analisar mas não sei escrever aquilo de uma maneira legal assim... para todo mundo entender.

Fonte: Banco de dados do Teletandem (grifos nossos)

Como podemos ver acima, a interagente, durante um momento longo de exposição, repete um discurso que pode ser encontrado nos mais diversos meios de interação social e que tem o respaldo de algumas figuras representativas do ensino formal.

Na figura 1, temos um exemplo de como esse discurso se propaga e sedimenta entre os brasileiros.

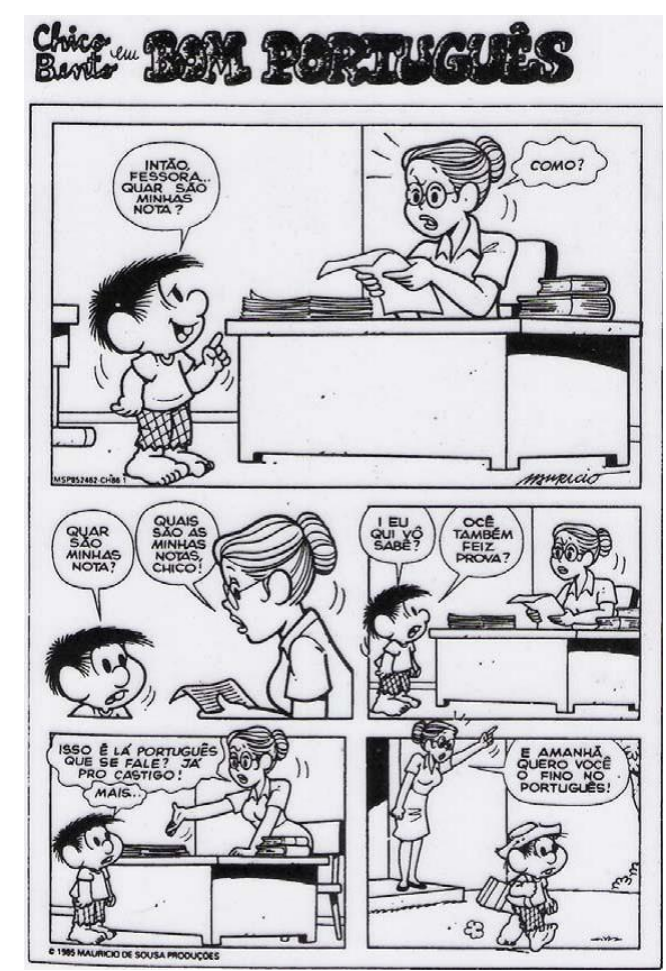

Figura 1 - A tirinha ${ }^{6}$ exemplifica como algumas variantes linguísticas, consideradas de menos prestígio, são tratadas por alguns falantes de língua portuguesa

\footnotetext{
${ }^{6}$ Disponível em: 〈http://goo.gl/44Axsj>.
} 
Não é incomum os brasileiros terem a concepção de que não sabem falar português, muito embora utilizem o idioma para se comunicar desde muito cedo sem ter grandes ruídos na comunicação que possam impossibilitar o diálogo. BraA reafirma o discurso de que obedecer à norma e à gramática seguem sendo referência para o "bom português" e não a efetivação da comunicação entre os integrantes de uma comunidade linguística.

$\mathrm{Na}$ Interação B, identificamos dois momentos em que paráfrases ocorrem. No primeiro, quando a interagente se refere aos nordestinos como sendo pessoas que constituem famílias numerosas e, no segundo, quando ela afirma que "nos lugares afastados" há dificuldade de acesso à informação e, portanto, pouco conhecimento.

Excerto 2 (de 23'50" a 25'19'): Preconceito regional

BrB: Ah é legal... [risos]... aqui... no Brasil... as famílias tão ficando cada vez.. menores... porque as pessoas... se casam... e e muitas vezes não querem ter filhos, aí elas vão cuidar da... carreira... é... aí... ou/ou tem um filho... então tá diminuindo muito assim... mas se a gente... se você... quando você for pro nordeste... você tem vontade de ir pro nordeste né? aí você vai ver que lá... as famílias são bem numerosas... é... cinco, seis, sete filhos... e até mais...

EstB: [risos]

BrB: é, é muito comum lá... é... é muito cultural assim... principalmente nas áreas mais... é... afastadas dos grandes centros... é... no interior... sabe? é... mais... não tem muito acesso à informação... então é, meninas com quinze anos têm... já tão grávidas... é bem preocupante

EstB: ah bem bem... é... é típica para ahn... para as famílias brasileiras... ahn... ter ahn... ahn... muitas... ahn.. membros e...

BrB: é, assim... tá mudando, assim... com o tempo tá diminuindo né... mas assim nos/nos... nos lugares mais afastados ainda é... a questão da informação ainda é meio complicada... no nordeste principalmente...

Fonte: Banco de dados do Teletandem (grifos nossos)

BraB mostra ter uma concepção dos nordestinos como sendo pessoas com menos informação e atrasadas. Tal discurso tem sido recorrente nas redes sociais, em alguns casos sendo necessária a intervenção da justiça no sentido de inibir discursos que alimentam afirmações como as que são vistas na figura 2. 


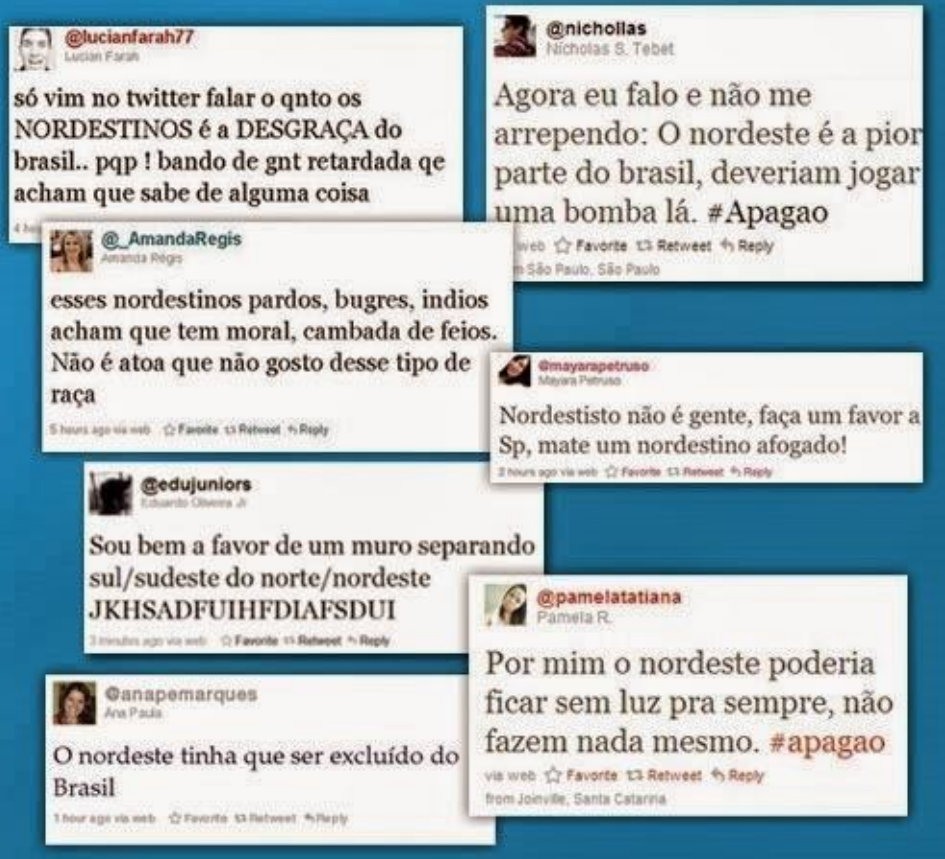

Figura 2 - Tweets da época das eleições presidenciais retirados da microblog Twitter $^{7}$

A Interação C foi a que mais suscitou questionamentos acerca das paráfrases. Como o par C conversava sobre as eleições presidenciais e a Copa do Mundo, pudemos verificar vários momentos em que $\mathrm{BraC}$ faz uso das paráfrases para mostrar sua opinião sobre os temas abordados. O excerto 3 foi retirado dos primeiros minutos da interação em português do par C. Antes de trocar a língua, do inglês para o português, EstC perguntou a BraC o que ela achava da imagem da presidente do Brasil como alguém que lutou contra a ditadura e que governa a favor dos pobres.

Excerto 3 (de 25'38" a 26'54"): Dilma e a pobreza

BraC: Eh, obrigada. Então, é, ela ela usa esse discurso pra dizer que ela ajuda os pobres e tal. Ok, mas o que que é ser pobre? Essa é a questão. No... numa... num... se você for pensar bem. Então, eu posso me considerar pobre ou eu não posso me considerar pobre? Então, ela, ela, ela usa muita subjetividade. Ela não é muito. Então, ela faz um discurso muito é, ideológico. E, é bonito. É, o discurso é bonito! Mas eu não sei se... Então, por isso que eu acho que ela é mais forte entre as pessoas que não têm uma formação ou que pararam os estudos. Porque, porque ah, ah, é eu não sei. É, é uma coisa bem complexa assim. Porque, ah, hoje é lógico, hoje é mais fácil as pessoas acessarem a faculdade, fazerem uma graduação e tudo mais e, e tudo isso. Mas há muitos anos atrás isso era muito difícil. Então, para uma pessoa que não tinha dinheiro, né? Ir pra uma.. Entrar numa faculdade era algo difícil. Então, ela trabalha, eu acho que ela trabalha com esse trauma todo. Ah, porque há vinte anos você não podia entrar na faculdade, hoje você pode. Então, tem, eu acredito tem muito disso.

Fonte: Banco de dados do Teletandem (grifos nossos)

\footnotetext{
${ }^{7}$ Disponível em: <https://goo.gl/VwZiQT>.
} 
A paráfrase que $\mathrm{BraC}$ retoma nesse excerto está relacionada ao discurso da então candidata Dilma Rousseff, considerada pela interagente brasileira como de esquerda partidária, conforme BraC afirma ao longo da interação. De acordo com ela, o discurso da candidata é ideológico, subjetivo e bonito, voltado para aqueles que não têm formação acadêmica. Com tais informações, infere-se que a participante pensa que os pobres são convencidos por discursos desse cunho. Dessa forma, ela retoma a paráfrase: esquerda ligada à defesa dos pobres e, consequentemente, direita relacionada à defesa dos interesses dos ricos, também apresentada em meios de comunicação social na época da interação, como podemos ver na figura abaixo:

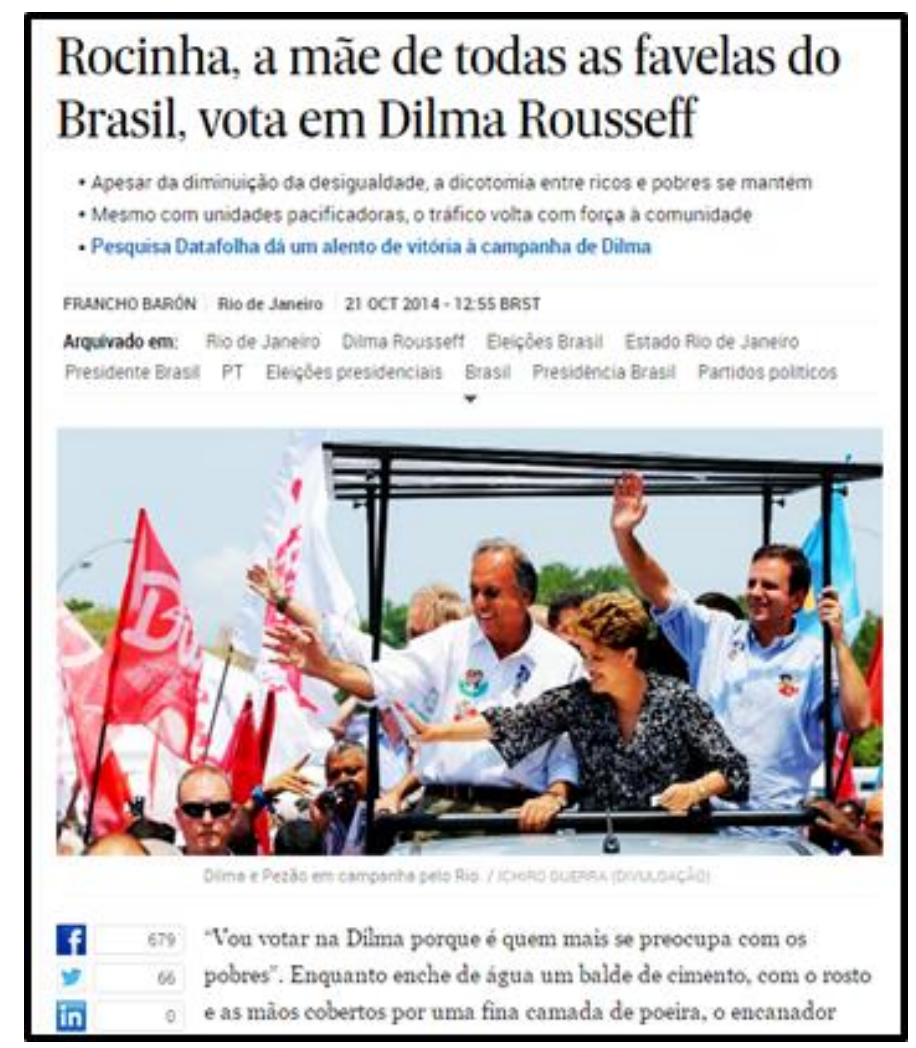

Figura 3 - Matéria publicada dia 21 de outubro de 2014 no El País ${ }^{8}$

Antes do excerto 4, BraC e EstC discutiam alguns casos de corrupção que aconteceram com pessoas do partido da candidata do PT.

\footnotetext{
${ }^{8}$ Disponível em: $\langle$ http://goo.gl/9I9y1R $>$.
} 
Excerto 4 (de 34'31” a 34'57'): PT = comunista = marxista

BraC: Então, é isso que é complicado. É muito complicado. Sem contar que existe toda a ideologia. Ideologia comunista, ideologia marxista, que é complicado, e por exemplo tem o apoio a Cuba. Todo mundo sabe que o Brasil apoia Cuba (risos), né?

EstC: Sim.

BraC: Então, construir um porto em Cuba, um porto muito grande. Sendo que o Porto de Santos tá caindo. Tá desmoronando de tão velho que tá.

Fonte: Banco de dados do Teletandem (grifos nossos)

O discurso retomado por $\mathrm{BraC}$ nesse trecho está ligado ao apoio financeiro do governo brasileiro, na época comandando pela candidata à reeleição, dado a Cuba, como foi amplamente divulgado pela mídia:

\section{Dilma oferece mais $R \$ 701$ milhões para financiar porto cubano}

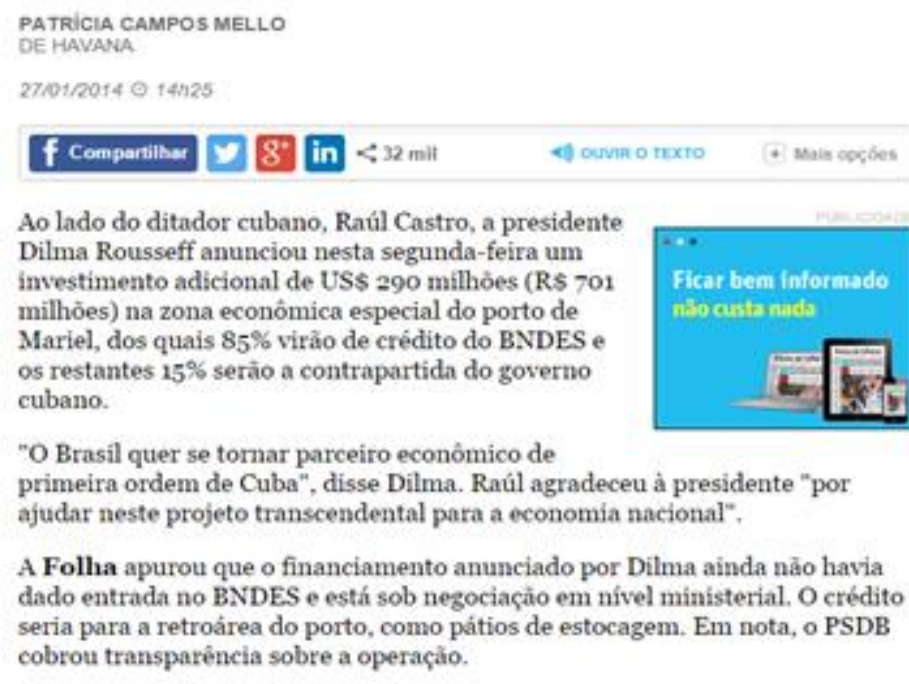

"O Brasil quer se tornar parceiro econômico de

primeira ordem de Cuba", disse Dilma. Raúl agradeceu à presidente "por ajudar neste projeto transcendental para a economia nacional".

A Folha apurou que o financiamento anunciado por Dilma ainda não havia dado entrada no BNDES e está sob negociaçào em nivel ministerial. O crédito seria para a retroárea do porto, como pátios de estocagem. Em nota, o PSDB cobrou transparência sobre a operaçăo.

Figura 4 - Matéria publicada na Folha ${ }^{9}$ (online) dia 27 de janeiro de 2014

No excerto, BraC justifica a existência de uma ideologia comunista e marxista do governo do PT em decorrência do apoio financeiro do governo brasileiro a Cuba. O comentário sobre a construção do porto acontece logo após conversa sobre casos de corrupção no Brasil. A relação entre a construção do porto em Cuba e a corrupção são

\footnotetext{
${ }^{9}$ Disponível em: 〈http://goo.gl/uKUpd5>.
} 
questões que, sob o ponto de vista de $\mathrm{BraC}$, depõem contra o governo, pois o caracterizam como corrupto e comunista.

Ao retomar esse discurso, BraC aproxima o governo brasileiro a Cuba, sugerindo que a ideologia comunista e marxista é corrupta, pois o partido é corrupto, nas palavras da interagente, "como é notório", repetindo discurso corrente entre os opositores à Dilma Rousseff, na época das eleições. Discurso que tem se repetido no decurso deste ano por ocasião do processo de impeachment. Por meio do uso da expressão "sem contar que", ela adiciona aos casos de corrupção, a ideologia marxista e comunista, como aspectos ruins e característicos do governo da candidata.

O excerto 5 foi retirado logo após a discussão das participantes sobre a construção do porto em Cuba.

Excerto 5 (de 36'35" a 37'56"): Dilma, Lula e terrorismo

BraC: É, mais isso, isso é, isso é ideologia, né? Todo mundo sabe que a Dil..., por exemplo, assunto polêmico foi o que ela pronunciou na ONU essa semana, na semana passada. Que ela, sobre os ataques ao Estado Islâmico, ela foi lá e falou um monte de coisa que não tem pé nem cabeça. (risos) Entende, não ter pé nem cabeça?

EstC: Sim.

BraC: Então. É porque a ideologia dela. É lógico que a gente sabe que guerra num, é lógico, ninguém quer guerra. Mas meu, tão cortando a cabeça de pessoas lá, sabe. É complicado. Eu acho que não tem que se meter onde ela não é chamada. Então, ela fizesse a abertura da ONU, eu não sei, eu num, eu acho que ela deveria ter uma postura menos é, sei lá. Eu acho que ela fala o que ela não sabe. Porque o Lula também, o Lula ele era parceiro do Ahmadinejad lá do Irã. Sabe? Ele era amigui...

EstC: Parcei, é?

BraC: Não, não, Não "parceiro" (gestos com a mão indicando aspas),

EstC: Oh!

BraC: Mas ele, tipo, ele tinha relação amistosa, tipo, o governo. Ele, ele se aproximou do Irã, numa época em que o Irã tava planejando construir bombas. Então, é assim, é porque é assim sempre a ideologia anticapitalista. Então, todo mundo que é anticapitalista me alio. Independente se essa pessoa é razoável ou não.

Fonte: Banco de dados do Teletandem (grifos nossos)

Nesse excerto, há a retomada de uma paráfrase, que não deixa de ser uma generalização: anticapitalista é terrorista. Essa afirmação, pelo que $\mathrm{BraC}$ diz, encontra raízes na compreensão de que, em um discurso da candidata na ONU, ela demonstrara seu posicionamento em prol dos terroristas o que, por consequência, tornara pública sua identificação também terrorista, além de comunista. Nesse período, a presidente Rousseff, inclusive, negou haver se colocado a favor dos terroristas, como podemos ver abaixo: 


\section{Dilma nega que tenha defendido diálogo com Estado Islâmico}

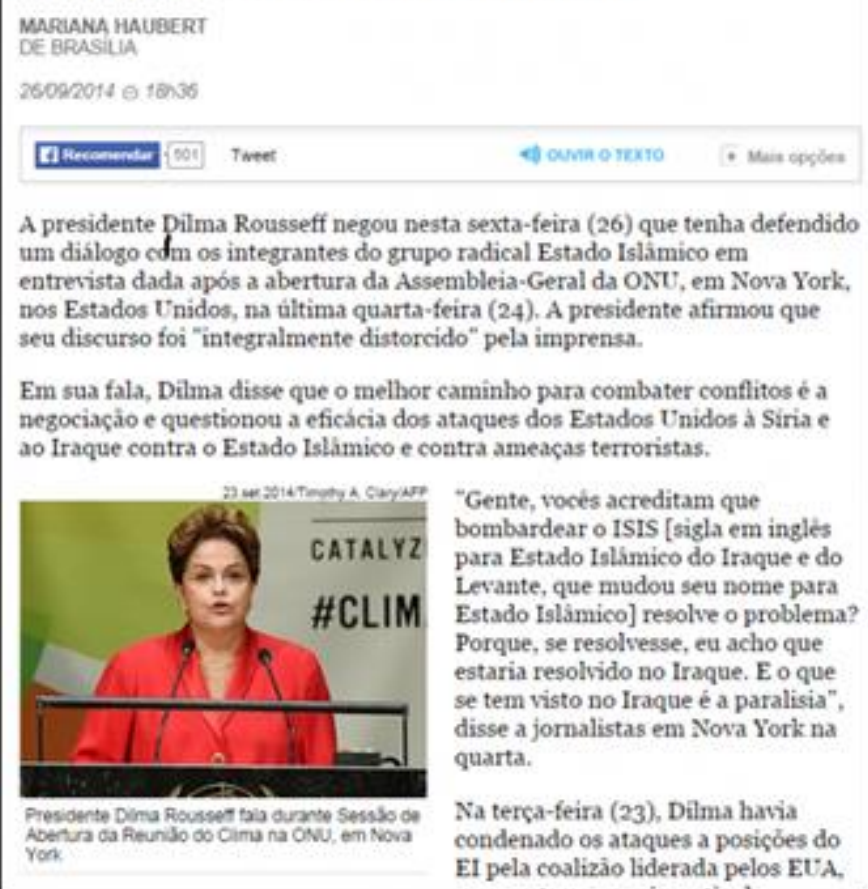

Em sua fala Dilma disse que o melhor caminho para combater conflitos é a negociaçào e questionou a eficácia dos ataques dos Estados Unidos a Siria e ao Iraque contra o Estado Islamico e contra ameaças terroristas.

Gente, vocés acreditam que bombardear o ISIS [sigla em inglès para Estado Islimico do Iraque e do Levante, que mudou seu nome para Estado Islamico] resolve o problema? Porque, se resolvesse, eu acho que estaria resolvido no Iraque. E o que se tem visto no Iraque é a paralisia", disse a jornalistas em Nova York na quarta.

Na terça-feira (23), Dilma havia condenado os ataques a posiçóes do EI pela coalizào liderada pelos EUA,

Figura 5 - Matéria publicada na Folha ${ }^{10}$ dia 26 de setembro de 2014

Para BraC, a ideologia marxista, comunista e anticapitalista justifica as ações do governo da presidente, o qual, segundo ela, é corrupto e terrorista. Pela repetição dessas ideias e termos, BraC generaliza, apresenta um quadro de um governo que levará o país à ruína, se posicionando claramente contra esse governo. Mesmo não parafraseando frases da oposição, a interagente parafraseia ideias amplamente divulgadas contra o governo, sem conscientemente ponderar quanto à veracidade dessas ideias.

Ao incorrer nos processos parafrásticos, na semana das eleições presidenciais, a participante brasileira se mostra interpelada pelo discurso da oposição difundido pela mídia na ocasião, como se pode perceber nas figuras 6 e 7 a seguir.

\footnotetext{
${ }^{10}$ Disponível em: 〈http://goo.gl/EfpiWD>.
} 


\section{Aécio usa "medo do comunismo" contra Dilma}

Figura 6 - Publicação do dia 22 de outubro de $2014^{11}$. Referência à candidata como comunista

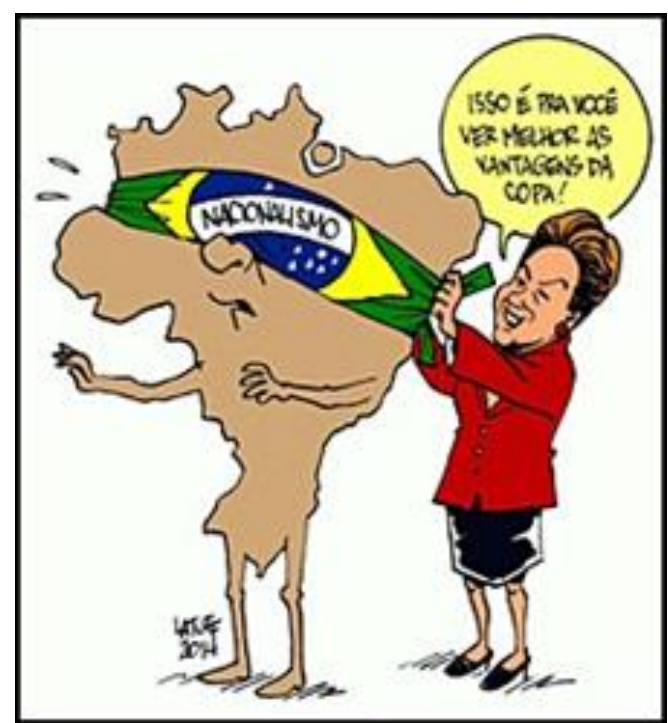

Figura 7 - Charge ${ }^{12}$ publicada em 2014 fazendo referência à Copa e seus benefícios

para o país

O excerto 6 abaixo foi retirado da Interação D, que também ocorreu no ano de 2014, em período próximo ao das eleições para presidente, senadores e governadores no Brasil. Antes do trecho citado, as interagentes estavam conversando sobre o candidato à reeleição do governo do Estado de São Paulo, Geraldo Alckmin:

Excerto 6 (de 30’24” a 31'36”): Escolas de São Paulo em pedaços

BraD: Olha não sei (risos). Eu espero que não. Porque, assim, é... pra quem é professor, é difícil aguentar o governo dele, é muito difícil...

EstD: Porque ele não é...

BraD: Não é bom pros professores, é difícil. E assim... é... ele, as escolas públicas aqui de São Paulo, estão muito, muito estragadas, sabe? Elas estão assim...a gente fala que estão caindo aos pedaços, já ouviu essa expressão? Caindo aos pedaços, vou escrever pra você.

Fonte: Banco de dados do Teletandem (grifos nossos)

\footnotetext{
${ }^{11}$ Disponível em: 〈http://goo.gl/2XHQwV $\rangle$.

${ }^{12}$ Disponível em: $\langle$ http://goo.gl/hr4d7c $>$.
} 
Como podemos observar, no excerto, a interagente brasileira repete o discurso parafrástico veiculado e sedimentado pela maioria dos brasileiros de que as escolas públicas são espaços que não recebem a manutenção adequada, chegando, assim, a se tornarem locais que estão "caindo aos pedaços". Esse tipo de discurso circula nos meios de comunicação e costuma se tornar manchete de jornais e programas de entretenimento e informação matinais, como no exemplo da figura 8 a seguir. No entanto, não é real que todas as escolas estejam no estado de abandono e depredação que o discurso da parceira brasileira deixa a entender.
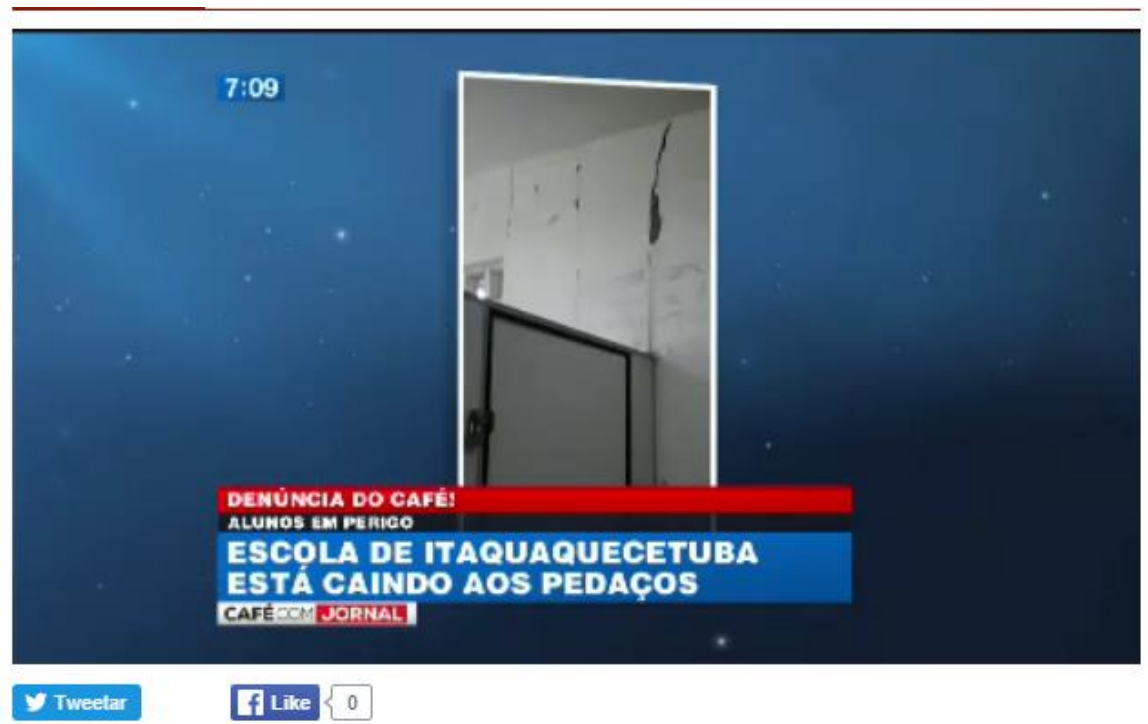

SP: Escola de Itaquaquecetuba está caindo aos pedaços

Uma escola pública municipal de Itaquaquecetuba, na Grande São Paulo, está caindo aos pedaços. A denúncia foi feita pelas mães de alunos. Elas reclamam das más condições em que se encontra o prédio. Segundo uma mãe, que já trabalhou nessa rede de ensino, uma cobra foi vista na cozinha da escola.

Figura 8 - Reportagem ${ }^{13}$ do dia 11.06.2014 na TV Bandeirantes

\section{Resultados e discussão: potenciais sequências de aprendizagem intercultural e mediação}

Inicialmente, é válido mencionar que as partes analisadas constituem apenas uma parte da interação, na qual ambos participantes falam em português. Teoricamente, essa parte é o momento oportuno para que a aprendiz estadunidense de português tenha oportunidade de praticar o idioma que está aprendendo. Como podemos ver nos excertos,

\footnotetext{
${ }^{13}$ Disponível em: <http://goo.gl/s5pkyy>.
} 
acima, houve pouca participação dos estadunidenses. As brasileiras têm os turnos maiores e, salvo alguns casos, há poucos momentos nos quais se discutem questões linguísticas. BraC, por exemplo, está tão envolvida na discussão sobre o tema político-econômicocultural que raras são as discussões sobre essas questões. Há momentos em que repetem equívocos da aprendiz de português, como no momento transcrito abaixo:

Excerto 7 (de 52'17” a 52’22”): (Des)preocupações linguísticas

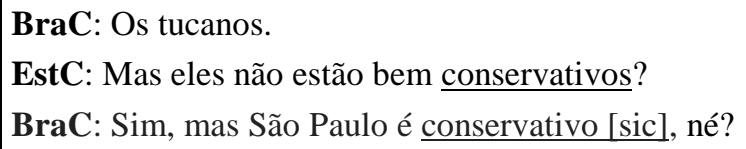

Fonte: Banco de dados do Teletandem (grifos nossos)

Respondendo às perguntas do estudo, apresentadas no início deste artigo, as paráfrases são as marcas discursivas encontradas nas sessões de Teletandem investigadas que evidenciaram os momentos de potenciais sequências de aprendizagem intercultural. A presença de discursos, como os apresentados, se torna oportunidade para a intervenção da mediação do professor de língua estrangeira, no sentido de contribuir para o desenvolvimento da competência intercultural de seus alunos.

Como pudemos ver, acima, sem uma mediação atuante, realizada após cada sessão de Teletandem, os parceiros, alunos de línguas estrangeiras, podem utilizar o tempo de maneira que não consigam agir reciprocamente, sem refletir acerca das questões culturais. Sem tais reflexões, os alunos podem não desenvolver a competência intercultural e até mesmo deixar à margem questões linguísticas que constituíram a motivação inicial para suas participações no Teletandem. Assim, essas sequências podem ser vistas pelo mediador como pontos de partida para problematização de questões interculturais.

Tais conteúdos auxiliam o parceiro a questionar-se sobre suas afirmações/generalizações, e mostram os múltiplos modos pelos quais nossos posicionamentos podem ser entendidos pelo outro. Discutir essas questões na mediação poderá ajudar o interagente a reconhecer que somos inconscientemente interpelados por outros discursos com os quais muitas vezes não concordamos por completo.

No caso de nosso estudo, as paráfrases serviram apenas para reforçar generalizações de um grupo preconceituoso linguística e regionalmente e contra alguns partidos políticos. A partir dessa identificação de sequências, a mediação poderia ser o 
espaço no qual se começa o processo de desenvolvimento constante da competência intercultural, com parceiros mais voltados para a colaboração, para a aprendizagem do outro, colocando-o em posição de equidade consigo mesmo.

\section{Como se fará isso?}

O papel do mediador neste processo de desenvolvimento da competência intercultural é, por assim dizer, indispensável. A proposta da problematização no grupo nos parece ser a alternativa mais eficaz, tendo no mediador a figura instigante da reflexão necessária para tal. No intuito de alcançar este objetivo, o mediador, após a identificação das PSAIs, criaria situações análogas de diálogo entre parceiros de Teletandem, para em seguida lançar os questionamentos.

Os participantes teriam oportunidade de colocar sua opinião a respeito do posicionamento discursivo dos parceiros envolvidos na PSAI, sendo orientados pelo mediador a perceber as construções discursivas que embasam as escolhas, lexicais inclusive, dos parceiros durante sua interação.

Destarte, o papel do mediador, sua cautela na identificação das PSAIs e a criação das situações análogas podem garantir o sucesso do desenvolvimento da competência cultural ou a solidificação de pré-conceitos sobre o outro e sobre a própria cultura.

Vale ressaltar que, caso o mediador entendesse ser melhor destacar as PSAIs, tentando mostrar explicitamente aos interagentes: a) as equivalências entre fenômenos das duas culturas; b) as ocasiões em que tentam explicar para o outro como compreendem os acontecimentos e ainda como c) o outro se adapta à suas contribuições, não estaria contribuindo para a reflexão que se faz imprescindível para o desenvolvimento da competência intercultural. Logo, entendemos ser fundamental que os interagentes cheguem eles mesmos às conclusões a respeito das construções discursivas e a explicitação de sua adesão a um ou outro discurso.

\section{Considerações finais}

Segundo Kramsch e Uryu (2014), os Terceiros Espaços são “zonas de colaboração e aprendizagem ou atividades reorganizadas para acomodar diferentes estilos de 
aprendizagem e para transformar conflito e falta de harmonia em diálogo frutuoso" (p. 213). A análise dos excertos apresentados aqui nos moveu a reflexões que nos inquietaram, assim como reiterou que o Teletandem pode ser um Terceiro Espaço, lugar de desconstrução e construção, propício para o desenvolvimento de competência intercultural (BELZ, 2003; HELM, 2009), apesar dos encontros normalmente não ultrapassarem as dez sessões.

Identificar os processos parafrásticos presentes nas sessões também nos indica as potenciais sequências de aprendizagem intercultural que, como uma implicação pedagógica a ser discutida nas mediações, será útil nesse processo. Desse modo, ao se deparar com questionamentos ${ }^{14}$ sobre a sua identidade e práticas culturais, assim como a do seu parceiro, o interagente poderá, nesse Terceiro Espaço, que não é o dele nem o do outro, perceber que muito do que acreditara ser "a verdade" se configura como construções sociais sedimentadas há anos e que não correspondem à realidade vivida por ele/ela. Nesse encontro dos diferentes, se percebendo assim, diverso do outro, com o auxílio da mediação, os parceiros terão oportunidade de descontruir "pré-conceitos", questionando-os (inclusive os que estão sedimentados a respeito de sua própria cultura e/ou cultura do outro).

As culturas de duas pessoas diferentes, com histórias diferentes, se encontram movidas pela disposição de aprender e de colaborar na aprendizagem de um idioma. Por oportunizar esse encontro, no entanto, o Teletandem poderá deixar de ser esse Terceiro Espaço, caso a mediação não exerça seu papel, pois normalmente tomamos a própria cultura como padrão, não questionamos nossos posicionamentos e terminamos por contribuir com os processos parafrásticos.

O que apontamos aqui são, portanto, implicações pedagógicas, considerando que não discutimos a mediação, principalmente por entendermos que precisaríamos de um espaço um pouco maior do que nos é permitido neste gênero e para o que nos propomos neste trabalho. Essas implicações surgiram das reflexões que a identificação das potenciais sequências de aprendizagem intercultural, a partir das paráfrases, nos suscitaram como oportunidade ímpar de desenvolvimento da capacidade de compreensão do outro como diferente de si. Isto considerando que, embora os interagentes

\footnotetext{
${ }^{14}$ Como por exemplo: Os brasileiros falam "errado" mesmo? Como conseguem se comunicar? A corrupção é característica de um partido político ou pode ser encontrado nos demais? Que imagem do "ser brasileiro" ou do "viver no Brasil" estou passando ao parceiro? Somos mesmo todos "iguais"?
} 
estadunidenses não tenham sido o foco neste artigo, é perceptível através dos excertos selecionados um posicionamento de acolhida das informações. Sem discordar, o 'outro' ouve sobre questões culturais e políticas, dando-nos indícios de seu respeito diante do outro que fala de si sobre quem o primeiro tem pouca ou nenhuma informação. Enquanto o estadunidense ouve, o brasileiro fala de si, colocando-se como diferente, pois ao usar diante do estrangeiro a expressão "porque no Brasil", o brasileiro está delimitando fronteiras culturais, onde as vivências e escolhas são diversas daquela que me ouve, caso contrário não haveria razão para estar explicando tais questões.

Nesse sentido, a identificação das potenciais sequências de aprendizagem intercultural pode contribuir de modo relevante para uma educação de línguas estrangeiras preocupada com o desenvolvimento da competência intercultural do aprendiz. Isso porque as tais sequências constituem excertos nos quais o mediador pode ver materializado linguisticamente, pelo discurso, questões culturais e pontos de vista.

Um professor de línguas estrangeiras que assuma a responsabilidade de mediar esses encontros interculturais precisará estar sempre atento aos posicionamentos de cada interagente que medeia. Ele próprio deverá se colocar num Terceiro Espaço para ajudar os interagentes a questionar seus posicionamentos diante do outro (estrangeiro) a respeito de suas respectivas culturas e pontos de vista, talvez suscitando questionamentos como: Que marcas linguístico-discursivas, que palavras/posicionamentos deixam a entender que a cultura do outro é superior e a minha inferior, mais corrupta e complicada? Qual o perigo das generalizações? O Teletandem, como Terceiro Espaço, pode ser um lugar perigoso, de cristalizações e ampliações de preconceitos - uma "faca de dois gumes", como afirma Telles (2015). No entanto, trata-se de um lugar ímpar para podermos efetivamente construir colaboração e autonomia no ensino e aprendizagem de língua estrangeira.

LOPES, Queila Barbosa; FRESCHI, Ana Carolina. Potential intercultural learning sequences in Teletandem: the importance of mediation. Revista do Gel, São Paulo, v. 13, n. 3, p. 49-74, 2016.

Abstract: From the characterization of Teletandem as a Third Space, where intercultural contact has a privileged territory (KRAMSCH; URYU, 2014), and of intercultural competence (BELZ, 2003) and paraphrases concepts (ORLANDI, 1987; 2000; PECHEUX, 1997), we discuss the importance of identifying potential sequences of intercultural learning (BORGHETTI et al., 2015) as opportunities for better self- 
understanding and self-criticism and development of intercultural competence from Teletandem mediation. In this way, our paper is at the interface among Language and Cultural Studies and Discourse Analysis of French line. Data were collected in 2011, 2012 and 2014 and their themes were linguistic and regional prejudice, presidential elections, FIFA World Cup in Brazil and generalizations about the situation of schools in São Paulo state. These issues based part of interactions and raised several paraphrases, which led us to some questions. Analyzing four Teletandem sessions of different language pairs, we could identify potential sequences of intercultural learning (PSILs), which demonstrate Teletandem potential as a space of this type of learning. Mediation sessions can significantly contribute to develop this competence, by helping to understand identities and what we know to be the identity we claim to have. This contribution may be effective through mediator's problem-action, which by using similar examples to those detected as PSILs, could make questions that help participants to reflect on their speech and try to put themselves in other's place.

Keywords: Teletandem. Interculturality. Intercultural learning sequence. Paraphrases. Mediation.

Submetido em: 30/05/2016.

Aceito em: 20/07/2016.

\section{Referências}

ANDRÉ, M. E. D. A. Etnografia da prática escolar. 4. ed. Campinas: Papirus, 2000.

ARANHA, S.; CAVALARI, S. M. S. A trajetória do projeto Teletandem Brasil: da modalidade institucional não-integrada à institucional integrada. The ESPecialist, v. 35, n. 2, p. 183-201, 2014.

BAUMAN, Z. Modernidade líquida. Tradução de Plínio Dentzien. Rio de Janeiro: Jorge Zahar Ed., 2001.

BELZ, J. A. Linguistic perspectives on the development of intercultural competence in telecollaboration. Language Learning \& Technology, v. 7, n. 2, p. 68-99, 2003.

BHABHA, H. K. O local da cultura. Tradução de Myriam Ávila. Belo Horizonte: UFMG, 1998.

BORGHETTI, C. et al. Interactions among future study abroad students: exploring potential intercultural learning sequences. Intercultural Education, v. 26, n. 1, p. 31-48, 2015.

BURNS, A. Collaborative Research for English Language Teachers. Cambridge: Cambridge University Press, 1999. 
BUTLER, J. Gender Trouble: Feminism and the subversion of identity. New York: Routledge Press, 1999.

BYRAM, M. Teaching and assessing intercultural communicative competence. Clevedon, England: Multilingual Matters, 1997.

DENZIN, N. K.; LINCOLN, Y. S. Planejamento da pesquisa qualitativa: teorias e abordagens. Tradução de Sandra Regina Netz. Porto Alegre: Artmed, 2007.

DERRIDA, J. Limited inc. Evanston, Illinois: Northewestern University Press, 1988.

GIVEN, L. M. (Ed.). The SAGE Encyclopedia of Qualitative Research Methods. v. 1 and 2. Los Angeles: SAGE Publications, 2008.

GÜNTHER, H. Pesquisa qualitativa versus pesquisa quantitativa: esta é a questão? Psicologia: Teoria e Pesquisa, v. 22, n. 2, p. 201-201, 2006.

HELM, F. Language and culture in an online context: what can learner diaries tell us about intercultural competence? Language and Intercultural Communication, v. 9, n. 2, p. 91-104, 2009.

KRAMSCH, C.; URYU, M. Intercultural contact, hybridity, and third space. In: JACKSON, J. (Ed.). The Routledge Handbook of Language and Intercultural Communication. New York: Routledge, 2014. p. 211-225.

MARTINS MOITEIRO, N. Action research on Teletandem: an analysis of virtual intercultural communication between students from Brazil and Germany. Diplomarbeit. Johannes Gütemberg Universität - Meinz. 2009.

MOITA LOPES, L. P. Pesquisa interpretativista em linguística aplicada: a linguagem como condição e solução. DELTA, São Paulo, v. 10, n. 2, p. 329-383, 1994.

ORLANDI, E. P. A linguagem e seu funcionamento: as formas do discurso. São Paulo: Brasiliense, 1987.

Análise de discurso: princípios e procedimentos. Campinas: Pontes, 2000.

PÊCHEUX, M. Semântica e discurso: uma crítica à afirmação do óbvio. Tradução de Eni Orlandi et al. Campinas: Editora da UNICAMP, 1997.

SALOMÃO, A. C. B. A cultura e o ensino de língua estrangeira: perspectivas para a formação continuada no projeto Teletandem Brasil. 2012. 270 f. Tese (Doutorado em estudos Linguísticos) - Instituto de Biociências, Letras e Ciências Exatas, Universidade Estadual Paulista, São José do Rio Preto, 2012.

TELLES, J. A. Teletandem Brasil: línguas estrangeiras para todos. Projeto de pesquisa. Faculdade de Ciências e Letras de Assis, Universidade Estadual Paulista, 2006. Disponível em: 
<http://www.Teletandembrasil.org/site/docs/Teletandem_BRASIL_completo.pdf>. Acesso em: 18 jun. 2014.

Teletandem: um contexto virtual, autônomo e colaborativo para aprendizagem de línguas estrangeiras no século XXI. Campinas: Pontes Editores, 2009.

Teletandem: Transculturalidade na comunicação on-line em línguas estrangeiras por webcam. Teletandem News, ano V, n. 1, p. 2-3, jan./abr. 2011.

Teletandem and performativity. Revista Brasileira de Linguística Aplicada, v. 15, p. 1-30, 2015.

TELLES, J. A.; FERREIRA, M. Teletandem: possibilidades, dificuldades e abrangências de um projeto de comunicação on-line de PLE. Revista Horizontes em Linguística Aplicada, v. 9, n. 2, p. 1-20, 2010.

WOODWARD, K. Identidade e diferença: uma introdução teórica e conceitual. In: SILVA, T. T. da (Org.). Identidade e Diferença: a perspectiva dos Estudos Culturais. Petrópolis: Editora Vozes, 2000.

ZAKIR, M. A. Cultura e(m) telecolaboração: uma análise de parcerias de Teletandem institucional. 2015. 234 f. Tese (Doutorado em Estudos Linguísticos) - Instituto de Biociências, Letras e Ciências Exatas, Universidade Estadual Paulista, São José do Rio Preto, 2015. 